\title{
The effect of video-based education on patient anxiety in men undergoing transrectal prostate biopsy
}

\author{
Huseyin Tarhan, MD; Ozgur Cakmak, MD, FEBU,; Elif Unal, MD; ${ }^{\dagger}$ Ilker Akarken, MD; Sitki Un, MD; \\ Rahmi Gokhan Ekin, MD; Ersin Konyalioglu, MD,* Cemal Selcuk Isoglu, MD; Ferruh Zorlu, MD*
}

*Tepecik Training and Research Hospital, Urology Department, Izmir-Turkey; ${ }^{\dagger}$ Tepecik Training and Research Hospital, Psychiatry Department, Izmir-Turkey; §Katip Celebi University, Ataturk Training and Research Hospital, Urology Department, Izmir-Turkey; ${ }^{*}$ Milas State Hospital, Urology Department, Mugla-Turkey

Cite as: Can Urol Assoc J 2014;8(11-12):e894-900. http://dx.doi.org/10.5489/cuaj.2208 Published online December 15, 2014.

\section{Abstract}

Introduction: We assess the effect of video-based education on patient anxiety during transrectal prostate biopsy.

Methods: A total of 246 patients who underwent transrectal prostate biopsy were prospectively enrolled in the study. Group 1 included 123 patients who received both written and video-based education, while Group 2 included 123 patients who received only written instructions regarding prostate biopsies. State-Trait Anxiety Inventory (STAI) was used to assess state and trait anxiety (STAI-S/T) After completing the STAI-S and STAI-T questionnaires, all patients in Group 1 received written information and video-based education and they again completed STAI-S before the biopsy. On the contrary, after completing the STAI-S and STAI-T questionnaires, the patients in Group 2 received only written information and then they completed the STAI-S before the biopsy. Moreover, a visual analog scale (VAS) was used to assess pain scores during digital rectal examination, probe insertion, periprostatic local anesthesic infiltration, and biopsy.

Results: No difference was noted between 2 groups regarding VAS scores. Comparing the 2 groups on baseline anxiety, we found that trait anxiety scores (STAI-T) were similar $(p=0.238)$. Preinformation STAI-S scores were similar in both groups $(p=0.889)$ and they both indicated high anxiety levels (score $\geq 42$ ). While postinformation STAI-S scores remained high in Group 2, post-information STAI-S scores significantly decreased in Group $1(p=0.01)$. Conclusions: Undergoing a prostate biopsy is stressful and may cause anxiety for patients. Video-based education about the procedure can diminish patient anxiety.

\section{Introduction}

Transrectal ultrasound (TRUS)-guided biopsy is the gold standard procedure to detect prostate cancer - the second most common cancer in men. ${ }^{1,2}$ However, this procedure could be stressful for patients. For patients, being evaluated for cancer using a painful or uncomfortable method can be a source of psychological distress. Gustafsson and colleagues investigated the possible negative psychological impact of prostate cancer screening. They found that patients undergoing screening experience emotional stress, resulting in elevated plasma cortisol levels. ${ }^{3}$

Before a medical or surgical procedure, patients should be provided with sufficient information so that levels of anxiety are diminished. . $^{40}$ However, the ideal way of providing this information is unclear. Although verbal information given by the clinician is the most common method, written material, ${ }^{11}$ leaflets, ${ }^{12}$ booklets, ${ }^{13}$ audiotapes,${ }^{8}$ or video-based education have also been proposed. ${ }^{4,6,11}$

Several studies have addressed the effect of video-based education on anxiety in patients undergoing different types of procedures. However none have have focused on the effect of video-based information regarding anxiety levels of patients scheduled for TRUS-guided biopsy.

In this study we assessed the impact of video-based education on patient anxiety during a TRUS-guided prostate biopsy procedure.

\section{Methods}

\section{Questionnaire}

State-Trait Anxiety Inventory (STAl) is a self-reported anxiety inventory with 2 separate 20 -item multiple choice subscales (see Appendix). The questionnaire assesses state anxiety (STAI-S: State (situational) anxiety; how one feels at the moment) and trait anxiety (STAI-T: Trait (baseline) anxiety; how one feels generally). Turkish validation of the STAI was performed by Oner and Le-Compte. ${ }^{14}$ STAI Scores of $\leq 35$ indicate no anxiety, scores of 36 to 41 indicate moderate anxiety and scores of $\geq 42$ indicate severe anxiety. ${ }^{15}$ The higher the score, the higher the anxiety level. The overall score ranges from 20 to 80 . This inventory was administered 
by a psychiatrist (EU) who was blinded to the information status of the patients.

\section{Study design}

After we obtained approval from the local ethics committee, we prospectively enrolled 246 consecutive patients scheduled for prostate biopsy as a result of elevated prostatespecific antigen (PSA) levels $(\geq 2.5 \mathrm{ng} / \mathrm{mL})$ and/or abnormal digital rectal examination (DRE).

We excluded patients with bleeding diathesis, anticoagulation treatment, painful perianal conditions (e.g., anal fissure, hemorrhoids), known lidocaine allergy, active urinary tract infection, a history of psychiatric disease, treatment with antidepressant drugs, a previous prostate biopsy history, as well patients who submitted incomplete or incorrectly filled questionnaires.

An informed consent was obtained prior to the biopsy after patients were counselled regarding the procedure.

Before the biopsy, computer-based randomization was used to assign patients to either group. Group 1 consisted of 123 patients who received both written and video-based education, while Group 2 included 123 patients with only written instructions regarding prostate biopsies. After completing STAI-S and STAI-T, all patients in Group 1 received written information and video-based education and they again completed STAI-S before the biopsy. On the contrary, after completing STAI-S and STAI-T, all patients in Group 2 received only written information and then they received STAI-S before the biopsy (Fig. 1). Moreover, visual analog scale (VAS) was used to assess the pain in both groups during the DRE, probe insertion, periprostatic local anaesthesic infiltration, and biopsy. The VAS scores ranged from 0 (no pain at all) to 10 (highest possible pain level).

\section{Video information}

All patients in Group 1 watched a video using a personal computer with a monitor in a private room accompanied by a clinical registered nurse or physician (FZ). In the video presentation, non-medical language was used to explain the whole procedure briefly to patients. The video presentation began with a definition of prostate cancer, then explained the need for prostate biopsy to diagnose prostate cancer. Afterwards, patient preparation, positioning, transrectal probe, biopsy gun, and sound of the biopsy gun during procedure were shown in detail. Finally, possible discomfort due to the procedure and possible complications of the biopsy were explained. The duration of the video was 6 minutes and 41 seconds.

\section{Prostate biopsy}

Prostate biopsies were performed with patients in the left decubitis position using the SonoScape SSI-2000 BW system (SonoScape, Co., Ltd, China ) ultrasound machine and a biplanar 7.5-MHz transrectal probe. Single doses of quinolone 1 hour before the procedure were administered as antimicrobial prophylaxis and bowel preparation with an enema was not routinely used. After $2 \%$ lidocaine gel was instilled to the rectum and was allowed at least 5 minutes to dwell, the probe was introduced per rectum. A 22-gauge spinal needle was introduced through the transrectal ultrasound probe and $10 \mathrm{~mL}$ of $2 \%$ lidocaine was injected into the junction

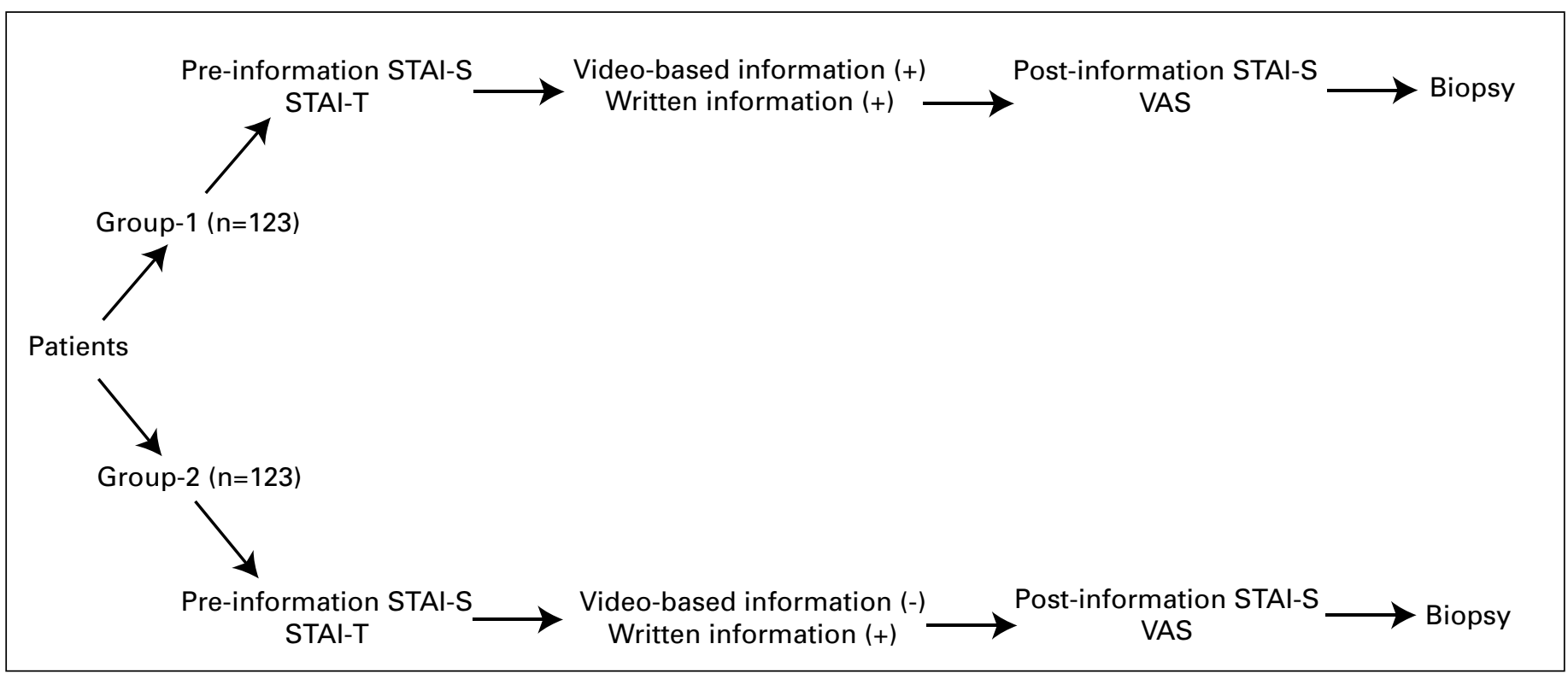

Fig. 1. Flowchart of the study. STATI-S: State-Trait Anxiety Inventory-State; STAI-T: State-Trait Anxiety Inventory-State; VAS: visual analog scale. 
between the prostate and seminal vesicle. After achieving an adequate level of analgesia, a standard 12-core biopsy was taken from each patient with 18-gauge 20-cm biopsy needle attached to an automated biopsy gun. VAS was used to assess pain during DRE, probe insertion, periprostatic local anaesthesic infiltration, and biopsy. All biopsies were performed by 2 urologists (SU and FZ).

\section{Statistical analysis}

Statical analysis was performed using SPSS for windows (version 15.0; SPSS Inc, Chicago, IL). Student's t-test was used to compare mean ages and mean pain scores during DRE, probe insertion, periprostatic local anesthesic infiltration, and biopsy. Trait and state anxiety scores were compared between groups using an independent-sample t-test. In each group, the mean pain scores among different trait anxiety levels were compared by means of the chi square test. Statistical significance was set at $p<0.05$.

\section{Results}

A total of 246 patients were enrolled in the study. The mean patient age was $64.12 \pm 7.98$ and $65.10 \pm 8.50$ in Group 1 and Group 2, respectively (Table 1). A statistically insignificant increase was noticed in Group 2 regarding VAS scores during DRE, probe insertion, periprostatic local anesthesic infiltration, and biopsy. When we compared groups regarding baseline anxiety scores, STAI-T were similar in both groups $(p=0.238)$.

Pre-information STAI-S scores were similar in both groups $(p=0.889)$ and both groups indicated high anxiety levels (score $\geq 42$ ). While post-information STAI-S scores indicated high anxiety levels in Group 2, post-information STAI-S scores decreased significantly in Group $1(p=0.01)$ (Table 2, Table 3).

\section{Discussion}

Prostate biopsy could cause considerable patient stress. ${ }^{3}$ About 20\% of men undergoing to prostate biopsy felt anxious and/or highly stressed prior to the biopsy. ${ }^{16}$ Pain, evaluation for possible malignancy and rectal route used by the probe are some possible reasons of the anxiety. Providing a detailed description of the diagnostic method or surgical procedure is one way to reduce anxiety. We investigated the effect of video-based education on patient anxiety during a transrectal prostate biopsy. Although there are several methods of evaluating anxiety, STAI is the standard method with the capability of assessing both situational (STAI-State) and general (STAI-Trait) anxiety. ${ }^{15}$

There are many studies on the effect of media-based health and procedure information on anxiety levels. To our knowledge this is the first report evaluating the effect of video-based information on anxiety in men undergoing TRUS-guided prostate biopsy. $4,6,11$

In our study we found similar STAI-T scores in both groups, indicating no difference in the general anxiety levels of patients.

Pre-information STAI-S scores (before receiving any written or video information) indicated high anxiety levels (score $\geq 42$ ) in both groups. This was not suprising and also consistent with the literature. ${ }^{3,16}$

An important finding of our study was the difference of

\begin{tabular}{|c|c|c|c|}
\hline & $\begin{array}{c}\text { Group } 1 \\
\text { Video and written information }\end{array}$ & $\begin{array}{c}\text { Group } 2 \\
\text { Only written information }\end{array}$ & $p$ value \\
\hline No. patients & 123 & 123 & \\
\hline Mean age & $64.12 \pm 7.98$ & $65.10 \pm 8.50$ & 0.347 \\
\hline \multicolumn{4}{|l|}{ VAS scores (mean) } \\
\hline DRE & $1.12 \pm 1.55$ & $1.40 \pm 1.66$ & 0.202 \\
\hline Probe insertion & $2.73 \pm 2.10$ & $3.08 \pm 2.16$ & 0.218 \\
\hline Local anaesthesic infiltration & $0.89 \pm 1.48$ & $0.93 \pm 0.95$ & 0.805 \\
\hline Biopsy & $0.58 \pm 0.95$ & $0.71 \pm 0.87$ & 0.288 \\
\hline \multicolumn{4}{|l|}{ STAI-T scores (mean) } \\
\hline Overall & $42.6 \pm 8.12$ & $41.3 \pm 8.50$ & 0.238 \\
\hline $\operatorname{Low}(\leq 35)$ & $30.4 \pm 3.88$ & $31.1 \pm 3.38$ & 0.173 \\
\hline Moderate (36-42) & $38.6 \pm 1.84$ & $39.1 \pm 1.65$ & 0.298 \\
\hline High $(\geq 42)$ & $47.5 \pm 4.80$ & $47.4 \pm 3.43$ & 0.151 \\
\hline \multicolumn{4}{|l|}{ STAI-T no. patients } \\
\hline $\operatorname{Low}(\leq 35)$ & $22(17.80 \%)$ & $25(20.30 \%)$ & \\
\hline Moderate (36-42) & $34(27.60 \%)$ & $32(26.00 \%)$ & \\
\hline High $(\geq 42)$ & 67 (54.40\%) & $66(53.50 \%)$ & \\
\hline
\end{tabular}




\begin{tabular}{|c|c|c|c|}
\hline & $\begin{array}{c}\text { Group } 1 \\
\text { Video and written information }\end{array}$ & $\begin{array}{c}\text { Group } 2 \\
\text { Only written information }\end{array}$ & $p$ value \\
\hline Pre-information STAI-S Scores (mean) & Ipsum & & \\
\hline Overall & $42.50 \pm 9.54$ & $42.10 \pm 9.09$ & 0.889 \\
\hline Low $(\leq 35)$ & $33.96 \pm 8.56$ & $34.60 \pm 8.82$ & 0.765 \\
\hline Moderate (36-42) & $40.37 \pm 9.60$ & $39.80 \pm 7.73$ & 0.830 \\
\hline High $(\geq 42)$ & $54.50 \pm 13.60$ & $53.60 \pm 13.80$ & 0.543 \\
\hline \multicolumn{4}{|l|}{ Pre-information STAI-S no. Patients } \\
\hline $\operatorname{Low}(\leq 35)$ & $66(53.65 \%)$ & $65(52.84 \%)$ & \\
\hline Moderate (36-42) & $28(22.76 \%)$ & $26(21.13 \%)$ & \\
\hline High $(\geq 42)$ & $29(23.57 \%)$ & $32(26.01 \%)$ & \\
\hline \multicolumn{4}{|l|}{ Post-information STAI-S scores (mean) } \\
\hline Overall & $35.70 \pm 7.65$ & $42.30 \pm 9.87$ & 0.01 \\
\hline Low ( $\leq 35)$ & $28.96 \pm 3.40$ & $33.89 \pm 8.53$ & 0.02 \\
\hline Moderate (36-42) & $37.88 \pm 9.50$ & $40.56 \pm 8.98$ & 0.04 \\
\hline High $(\geq 42)$ & $42.98 \pm 9.55$ & $54.49 \pm 12.90$ & 0.03 \\
\hline \multicolumn{4}{|l|}{ Post-information STAI-S no. of patients } \\
\hline Low $(\leq 35)$ & $64(52.03 \%)$ & $63(51.21 \%)$ & \\
\hline Moderate (36-42) & $29(23.57 \%)$ & $28(22.76 \%)$ & \\
\hline High $(\geq 42)$ & $30(24.39 \%)$ & 32 (30.89\%) & \\
\hline
\end{tabular}

STATI-S: State-Trait Anxiety Inventory-State; STAI-T: State-Trait Anxiety Inventory-State; VAS: visual analog scale; DRE: digital rectal examination.

post-information STAI-S scores between the 2 groups. While the post-information STAI-S scores remained stable in patients who received only written information (Group 2) $(p=0.89)$, there was a significant decrease of post-information STAI-S scores in patients who received both written and video education (Group 1) ( $p=0.01$ ). It can be concluded that offering only written information about the biopsy procedure may not be sufficient to diminish patient anxiety; providing a detailed discription of the procedure using a audio-visual medium, is important for relieving stress and decreasing anxiety. Similarly, Stanle and colleagues found that additional written or verbal information did not improve a patient's understanding of the risks and complications of the procedure. ${ }^{17}$

Although we found a significant decrease of post-information STAI-S scores in Group 1, the proportion of patients scoring low, moderate and high levels of anxiety was essentially the same in both groups. When we compared the pre and post information STAI-S scores of Group 1 patients, it would appear that the most striking difference was observed in those who score high at the onset for situational anxiety. These were the patients who would potentially benefit most from added a video component before the biopsy.

Although not objectively demonstrated, We found that patients who received both written and video information (Group 1) were more ready for the biopsy and were more satisfied after the procedure - although this was not objectively demonstrated. These observational findings may be studied with objective and validated inventories in future studies.

We also used VAS to assess pain in both groups during DRE, probe insertion, periprostatic local anesthesic infiltration, and biopsy. A statistically insignificant increase was noticed in Group 2 regarding VAS scores. Taken together with significant decrease of post-information STAI-S scores in Group 1, video-based information affects only patient anxiety but not pain perception.

From a different perspective, some studies investigated whether more extensive information increases anxiety levels. Inglis and colleagues questioned whether detailed information about the potential complications of general anesthesia the night before surgery increases anxiety. They found that it did not. ${ }^{18}$

Due to the subjective nature of anxiety, describing it may not always be accurate. Using muliple choice questions may be inadequate to assess feelings - this is a limitation of our study. Moreover, anxiety- and pain-related vital signs, such

\section{Table 3. Changes of STAI-S scores with information in Group1 and Group 2}

\begin{tabular}{lccc}
\multicolumn{4}{l}{ Table 3. Changes of STAI-S scores with information in Group1 and Group 2} \\
\hline & Pre-information STAI-S score (mean) & Post-information STAI-S score (mean) & p value \\
\hline Group 1 & $42.5 \pm 8.54$ & $35.7 \pm 7.65$ & 0.01 \\
Group 2 & $42.1 \pm 9.09$ & $42.3 \pm 5.87$ & 0.898 \\
\hline
\end{tabular}


as heart rate, respiratory rate, and blood pressure, were not addressed in our study and may be evaluated as supportive findings in future studies.

\section{Conclusion}

Prostate biopsy is a stressful event and may cause anxiety for patients. The present study is the first randomized controlled study comparing written and video-based education on patient anxiety during transrectal prostate biopsy. Video-based education about the biopsy can diminish patient anxiety. Future trials are needed to identify patient subgroups who would benefit most from video-based information.

Competing interests: Authors declare no competing financial or personal interests.

This paper has been peer-reviewed.

\section{References}

1. Jemal A, Bray F, Center MM, et al. Global cancer statistics. CA Cancer J Clin 2011;61:69-90. http:// dx.doi.org/10.3322/caac.20107

2. Geybels MS, Neuhouser ML, Stanford JL. Associations of tea and coffee consumption with prostate cancer risk. Cancer Causes Control 2013;24:941-8. hittp://dx.doi.org/10.1007/s10552-013-0170-8.

3. Gustafsson 0 , Theorell T, Norming U, et al. Psychological reactions in men screened for prostate cancer. BJU Int 1995;75:631-6. http://dx.doi.org/10.1111/j.1464-410X.1995.tb07422.x

4. Agre P, Kurtz RC, Krauss BJ. A randomized trial using video-tape to present consent information for colonoscopy. Gastrointest Endosc 1994;40:271-6. http://dx.doi.org/10.1016/S0016-5107(94)70054-0

5. Luck A, Pearson $S$, Maddern $G$, et al. Effects of video information on precolonoscopy anxiety and knowledge: A randomized trial. Lancet 1999;354:2032-5. http://dx.doi.org/10.1016/S0140-6736(98) 10495-6

6. Herrmann KS, Kreuzer H. A randomized prospective study on anxiety reduction by preparatory disclosure with and without video film show about a planned heart catheterization. Eur Heart J 1989;10:753-7.

7. Peterson M. Patient anxiety before cardiac catheterization: an intervention study. Heart Lung 1991;20:6437.

8. Auerbach SM, Kendall PC. Sex difference in anxiety response and adjustment to dental surgery: Effects of general vs specific preoperative information. J Clin Psychol 1978;34:309-13. http://dx.doi. org/10.1002/1097-4679(197804)34:2<309::AID-JCLP2270340209>3.0.C0;2-N

9. Poroch D. The effect of preparatory patient education on the anxiety and satisfaction of cancer patients receiving radiation therapy. Cancer Nurs 1995;18:206-14. http://dx.doi.org/10.1097/00002820199506000-00005

10. Leckie J. The effects of informational intervention on state of anxiety and satisfaction in patients undergoing bone scan. Nudl Med Commun 1994;15:921-7. http://dx.doi.org/10.1097/00006231-19941100000011

11. Levy N, Landmann L, Stermer E, et al. Does a detailed explanation prior to gastroscopy reduce the patient's anxiety? Endoscopy 1989;21:263-5. http://dx.doi.org/10.1055/s-2007-1012965

12. Howells RE, Dunn PD, Isasi T, et al. Is the provision of information leaflets before colposcopy beneficial? A prospective randomized study. Br J Obstet Gynaecol 1999;106:528-34. http://dx.doi. org/10.1111/i.1471-0528.1999.tb08319.x

13. Lanius $M$, Zimmermann $P$, Heegewaldt $H$, et al. Does an information booklet on gastrointestinal endoscopy reduce anxiety for these examinations? Results of a randomized study with 379 patients. Gastroenterology 1990;28:651-5

14. Oner N, Le-Compte A. Handbook of the Stait-Trait Anxiety Inventory [in Turkish]. 2nd ed. Istanbul: Bogazici University Press; 1985.

15. Marteau TM, Bekker H. The development of a six-item short-form of the state scale of the Spielberg State-Trait Anxiety Inventory (STAl). Br J Clin Psychol 1992;31:301-6. http://dx.doi. org/10.1111/i.2044-8260.1992.tb00997.x

16. Macefield RC, Metcalfe C, Lane JA, et al. Impact of prostate cancer testing: An evaluation of the emotional consequences of a negative biopsy result. Br J Cancer 2010;102:1335-40. http://dx.doi.org/10.1038/ si.bic. 6605648

17. Stanley BM, Walters DJ, Maddern GJ. Informed consent: How much information is enough? Aust N Z J Surg 1998;68:788-91. http://dx.doi.org/10.1111/j.1445-2197.1998.tb04678.x

18. Inglis $S$, Farnill $D$. The effects of providing preoperative statistical anesthetic-risk information. Anaesth Intensive Care 1993;21:799-805.

Correspondence: Dr. Ozgur Cakmak, Tepecik Training and Research Hospital, Urology Department, Izmir-Turkey; drozgurcakmak577@yahoo.com 


\section{Appendix: STUDY QUESTIONNAIRE}

\section{SELF-EVALUATION QUESTIONNAIRE STAI Form Y-1}

Please provide the following infomration:

Name

Date

Age

DIRECTIONS:

A number of statements which people have used to describe themselves are given below. Read each statement and then circle the appropriate number to the right of the statement to indicate how you feel right now, that is, at this moment. There are no right or wrong answers. Do not spend too much time on any one statement but give the answer which seems to describe your present feelings best.

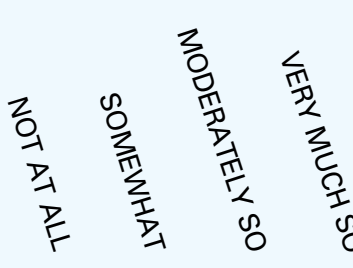

1. I fee calm

2. I feel secure

3. I am tense

4. I feel strained

5. I feel at ease

6. I feel upset.

7. I am presently worrying over possible misfortunes

8. I feel satisfied

9. I feel frightened

10. I feel comfortable

11. I feel self-confident.

12. I feel nervous

13. I am jittery

14. I feel indecisive

15. I am relaxed

16. I feel content

17. I am worried

18. I feel confused

19. I feel steady

20. I feel pleasant.

1

1

1

1

1

1

1

1

1 
Please Provide the following infomration:

Name

Date

\section{DIRECTIONS:}

A number of statements which people have used to describe themselves are given below. Read each statement and then circlt the appropriate number to the right of the statement to indicate how you feel right now, that is, at this moment. There are no right or wrong answers. Do not spend too much time on any one statement but give the answer which seems to describe your present feelings best.

21. I feel pleasant.

22. I feel nervous and restless

23. I feel satisfied with myself

24. I wish I could be as happy as others seem to be

25. I feel like a failure

26. I feel rested

27. I am "calm, cool, and collected".

28. I feel that difficulties are piling up so that I cannot overcome them

29. I worry too much over something that really doesn't matter

30. I am happy

31. I have disturbing thoughts

32. I lack self-confidence

33. I feel secure.

34. I make decisions easily

35. I feel inadequate

36. I am content

37. Some unimportant thought runs through my mind and bothers me

38. I take disappointments so keenly that I can't put them out of my mind

39. I am a steady person

40. I get in a state of tension or turmoil as I think over my recent concerns and interests

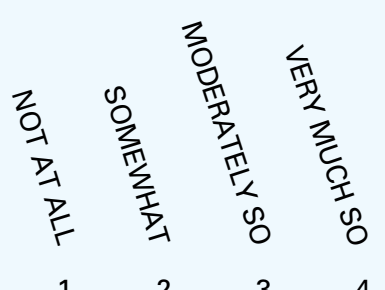

$\begin{array}{llll}1 & 2 & 3 & 4\end{array}$

$\begin{array}{llll}1 & 2 & 3 & 4\end{array}$

$1 \quad 2 \quad 3 \quad 4$

$1 \quad 2 \quad 3 \quad 4$

$1 \quad 2 \quad 3 \quad 4$

$12 \quad 3 \quad 4$

$1 \quad 2 \quad 3 \quad 4$

$1 \quad 2 \quad 3 \quad 4$

$12 \quad 3 \quad 4$

$12 \quad 3 \quad 4$

$\begin{array}{llll}1 & 2 & 3 & 4\end{array}$

$1 \quad 2 \quad 3 \quad 4$

$\begin{array}{llll}1 & 2 & 3 & 4\end{array}$

$\begin{array}{llll}1 & 2 & 3 & 4\end{array}$

$\begin{array}{llll}1 & 2 & 3 & 4\end{array}$

$\begin{array}{llll}1 & 2 & 3 & 4\end{array}$

$\begin{array}{llll}1 & 2 & 3 & 4\end{array}$

$\begin{array}{llll}1 & 2 & 3 & 4\end{array}$

$\begin{array}{llll}1 & 2 & 3 & 4\end{array}$

$\begin{array}{llll}1 & 2 & 3 & 4\end{array}$

STAIP-AD Test Form $Y$ www.mindgarden.com 